\title{
Identifying contraindications to resection in patients with pancreatic carcinoma: The role of endoscopic ultrasound
}

\author{
Maurits J Wiersema MD
}

MJ Wiersema. Identifying contraindications to resection in patients with pancreatic carcinoma: The role of endoscopic ultrasound. Can J Gastroenterol 2002;16(2):109-114.

OBJECTIVE: To present recently published material comparing the performance of endosonography relative to other imaging modalities when evaluating the patient with a suspected or known pancreas carcinoma.

METHODS: MEDLINE was searched using the terms 'endosonography' and 'pancreas neoplasms'. References from retrieved papers were reviewed to identify other reports. Emphasis was placed on peer-reviewed material published within the past three years that included comparison with other imaging modalities.

RESULTS: Despite advances in cross-sectional imaging modalities, endosonography remains the most sensitive and specific method for identifying pancreatic mass lesions. The resectability of pancreatic carcinoma is best determined with dual-phase helical computed tomography, although endosonography may be slightly more accurate for lymph node assessment. Endoscopic ultrasound-guided fine needle aspiration biopsy has a high sensitivity $(93 \%)$ and specificity $(100 \%)$ when used in patients with masses in whom pancreatic cancer is suspected but prior biopsies have been negative.
CONCLUSIONS: Endosonography helps in the diagnosis of pancreatic neoplasms through definitive inclusion or exclusion of a mass lesion as well as biopsy confirmation of malignancy. The role of endosonography in the determination of resectability has been eclipsed by dual-phase helical computed tomography. However, endoscopic ultrasound with fine needle aspiration of nonperitumoral lymph nodes may identify advanced disease with sufficient frequency to justify its routine use in patients with lesions that are thought to be resectable based on helical computed tomography.

Key Words: Biopsy; Computed tomography; Endosonography; Pancreas adenocarcinoma; Pancreas neoplasm

Contre-indications à la résection chez les patients atteints d'un cancer du pancréas : rôle de l'échographie endoscopique

OBJECTIF : Présenter des articles récents qui comparent la performance de l'endosonographie à celle d'autres techniques d'imagerie utilisées pour évaluer les patients atteints ou peut-être atteints d'un cancer du pancréas.

voir page suivante

Division of Gastroenterology and Hepatology, Mayo Clinic, Rochester, Minnesota, USA

Correspondence: Dr Maurits J Wiersema, Eisenberg 8A, Mayo Clinic, 200 First Street Southwest, Rochester, Minnesota 55905, USA.

Telephone 507-266-6931,fax 507-266-3939, e-mail wiersema.maurits@mayo.edu

Received for publication December 3, 2001. Accepted December 3, 2001 
MÉTHODES : Une recherche a été effectuée dans MEDLINE à l'aide des termes « endosonography » (endosonographie) et «pancreas neoplasms » (néoplasmes du pancréas). Nous avons examiné les références des articles extraits pour trouver d'autres rapports. Un intérêt particulier a été porté aux articles revus par les pairs et publiés au cours des trois dernières années, dans lesquels les auteurs établissaient des comparaisons avec d'autres techniques d'imagerie.

RÉSULTATS : Malgré les progrès réalisés en matière de techniques d'imagerie en coupe transversale, l'endosonographie demeure le moyen de détection des lésions du pancréas le plus sensible et le plus précis. La résectabilité du cancer du pancréas est mieux définie par la tomodensitométrie hélicoïdale biphasée, mais l'endosonographie peut s'avérer un peu plus précise pour évaluer l'état des ganglions lymphatiques. La biopsie par aspiration à l'aiguille fine sous guidage endo-échographique offre une sen- sibilité (93\%) et une spécificité élevées (100\%) chez les patients qui présentent des masses et que l'on croit atteints d'un cancer du pancréas mais chez qui les biopsies antérieures se sont révélées négatives.

CONCLUSIONS : L'endosonographie aide à diagnostiquer les néoplasmes du pancréas en permettant d'établir de façon définitive la présence ou non d'une lésion tout comme la biopsie confirme la malignité. Le rôle de l'endosonographie dans la détermination de la résectabilité a été supplanté par la tomodensitométrie hélicoïdale biphasée. Par ailleurs, la biopsie des ganglions lymphatiques périphériques non péritumoraux par aspiration à l'aiguille fine sous guidage endo-échographique peut permettre de déceler des cancers rendus à un stade avancé, et ce, assez souvent pour en justifier l'utilisation systématique chez les patients présentant des lésions jugées résécables d'après la tomodensitométrie hélicoïdale.

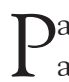
atients presenting with symptoms and signs of a pancreatic neoplasm frequently initially undergo transabdominal ultrasound or computed tomography (CT). Often, laboratory data corroborate the clinical impression of a pancreatic neoplasm, and the diagnostic evaluation is rather limited in this setting. Imaging subsequently focuses on determining the presence or absence of a mass lesion. Once a mass lesion is identified, the morbidity and mortality associated with surgical exploration can be avoided in patients with advanced disease by determining the lesion's resectability. The present review covers the role of endoscopic ultrasound (EUS) in the evaluation of the patient with a pancreatic mass.

\section{IDENTIFICATION OF THE MASS LESION}

Patients presenting with refractory upper abdominal pain may undergo CT or ultrasound imaging that demonstrates a pancreatic 'mass' (or more commonly a 'fullness'). The significance of this finding rests in the ominous prognosis of patients with pancreatic carcinoma. There is an obligation to investigate this radiological finding fully so that the therapy of a potentially curable neoplasm is not delayed and to ensure that a normal variant is not surgically treated. The former goal requires imaging tests with high sensitivity, whereas the latter necessitates high specificity.
The sensitivity and specificity of various imaging procedures for detecting or excluding pancreatic neoplasms have been studied extensively. Most importantly, recent studies have evaluated the performance of EUS, helical CT, state of the art magnetic resonance imaging (MRI) and positron emission tomography (PET) $(1,2)$. Despite advances in other techniques, EUS is the most sensitive and specific technique (Table 1) (1-5). The sensitivity of EUS ranges from $93 \%$ to $100 \%$, and the specificity from $33 \%$ to $100 \%$. The low specificity of $33 \%$ for EUS was reported by Legmann et al (2), whose study included only three patients without tumours. In a larger series, Muller et al (1) demonstrated a higher specificity of EUS (16 of 16, 100\%) than of CT (nine of $14,64 \%$ ). In this same series, for tumours smaller than $2 \mathrm{~cm}$, the sensitivity was $90 \%$ (nine of 10 tumours) with EUS, $40 \%$ (four of 10 tumours) with CT and $33 \%$ (three of nine tumours) with MRI (1).

In patients with suspected small pancreatic lesions on CT, Bender et al (6) reported that EUS was helpful in distinguishing normal subjects from patients with neoplasms. For small lesions, the specificity of EUS (88\%) was twice that of dynamic CT (41\%), which supports the role of EUS in confirming the presence of a tumour. Further studies are needed to determine whether dual-phase helical CT has a superior specificity.

\section{TABLE 1}

Sensitivity and specificity of imaging techniques in detecting pancreatic tumours

\begin{tabular}{|c|c|c|c|c|c|c|c|c|c|}
\hline \multirow[b]{2}{*}{ Author (reference) } & \multirow[b]{2}{*}{$\mathbf{n}$} & \multicolumn{2}{|c|}{ EUS (\%) } & \multicolumn{2}{|c|}{ CT (\%) } & \multicolumn{2}{|c|}{ MR (\%) } & \multicolumn{2}{|c|}{ PET (\%) } \\
\hline & & Sensitivity & Specificity & Sensitivity & Specificity & Sensitivity & Specificity & Sensitivity & Specificity \\
\hline Muller et al (1) & 49 & 94 & 100 & 69 & 64 & 83 & 100 & - & - \\
\hline Legmann et al $(2)^{*}$ & 33 & 100 & 33 & 92 & 100 & - & - & - & - \\
\hline Gress et al (3) & 81 & 100 & - & 74 & - & - & - & - & - \\
\hline Mertz et al (4) & 35 & 93 & 75 & 53 & 25 & - & - & 87 & 50 \\
\hline Midwinter et al $(5)^{\star}$ & 48 & 97 & - & 76 & - & - & - & - & - \\
\hline
\end{tabular}


TABLE 2

Sensitivity and specificity of endoscopic ultrasound (EUS) and endoscopic retrograde cholangiopancreatography (ERCP) in differentiating between benign and malignant pancreatic masses

\begin{tabular}{lccccc}
\hline & \multicolumn{2}{c}{} & EUS & \multicolumn{2}{c}{ ERCP } \\
Author (reference) & $\mathbf{n}$ & Sensitivity (\%) & Specificity (\%) & Sensitivity (\%) & Specificity (\%) \\
\hline Baron et al (12) & 105 & 95 & 88 & - & - \\
Glasbrenner et al (11) & 95 & 78 & 93 & 81 & 88 \\
Rosch et al (10) & 102 & 76 & 46 & 86 & 62 \\
\hline
\end{tabular}

Reproduced with permission from reference 38

\section{DISTINGUISHING INFLAMMATORY FROM NEOPLASTIC PANCREATIC MASS LESIONS}

Neoplastic pancreatic mass lesions can usually be diagnosed easily by presenting symptoms, signs and imaging studies. More difficult challenges are posed by mass lesions that occur in the setting of chronic pancreatitis or when the initial presentation of the mass lesion is associated with an episode of pancreatitis. Ancillary testing may help determine the malignant potential of the mass lesion in these situations.

Assessment of tumour markers may be helpful. CA 19-9 was found to have the greatest sensitivity $(70 \%)$ and specificity $(87 \%)$ for the diagnosis of pancreatic cancer when a cutoff value of $70 \mathrm{U} / \mathrm{mL}$ was used (7). Substantial elevations in CA 19-9 can also be seen, however, with acute cholangitis secondary to gallstones or to malignant biliary obstruction $(8,9)$. Although elevations of CA 19-9 strongly support the diagnosis of an adenocarcinoma of the pancreas (7), consideration of adjuvant therapy should be based on a tissue diagnosis.

The high resolution imaging afforded by EUS may permit the identification of features that assist in distinguishing benign from malignant pancreatic mass lesions. EUS findings that are suggestive of an inflammatory mass include diffuse inflammatory changes throughout the pancreas (inhomogeneous echo pattern, calcification with or without duct lithiasis, echopoor peripancreatic fat stranding and cysts), whereas malignancy is characterized by invasion of adjacent organs, an echopoor irregular mass, echopoor enlarged regional lymph nodes and evidence of distant metastases $(10,11)$. Baron et al $(12)$ demonstrated a high sensitivity (95\%) and specificity (88\%) of EUS when used to distinguish malignant from benign pancreatic masses (Table 2). Unfortunately, these results have not been confirmed by other studies that have shown specificities of EUS ranging from $46 \%$ to $93 \%(10,11)$.

Endoscopic retrograde cholangiopancreatography (ERCP) was not superior to EUS in either of two studies $(10,11)$, and resulted in complications in up to $4 \%$ of patients (11). PET using F-18-fluoro-2-deoxy-D-glucose (FDG) has recently been investigated for this purpose. The increased uptake of FDG in inflammatory lesions has limited the applications of PET, but more recent investigations suggest that delayed imaging may enhance its specificity. Nakamoto et al (13) reported a diagnostic accuracy of
TABLE 3 Tumour and lymph node staging accuracy in
pancreatic cancer: Endoscopic ultrasound (EUS)
versus computed tomography (CT)

\begin{tabular}{lccccc} 
& \multicolumn{3}{c}{ T stage } & \multicolumn{2}{c}{ N stage } \\
Author (reference) & $\mathbf{n}$ & EUS (\%) & $\mathbf{C T}(\%)$ & EUS (\%) & $\mathbf{C T}(\%)$ \\
\hline Legmann et al (2) $^{\dagger}$ & 22 & 90 & 86 & 86 & 77 \\
Midwinter et al (5) & 23 & - & - & $74^{\ddagger}$ & $65^{\ddagger}$ \\
Gress et al (3)§ & 81 & 85 & 30 & 72 & 55 \\
\hline
\end{tabular}

${ }^{*}$ TNM staging as per The American Joint Committee on Cancer (38); ${ }^{\dagger}$ Distant

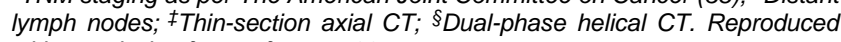
with permission from reference 38

91.5\% when they evaluated 47 patients with suspected pancreatic carcinoma (27 malignant, 20 benign) using $2 \mathrm{~h}$ delayed imaging.

\section{DETERMINATION OF RESECTABILITY}

Accurate staging of pancreatic cancer is essential for determining which patients may benefit from surgery. Vascular and lymph node invasion are important prognostic factors that should be identified before surgery. Early reports (14-16) showed that the accuracy of EUS for preoperative staging of pancreatic cancer (85\% to $100 \%$ ) was superior to that of dynamic CT (64\% to 66\%) and transabdominal ultrasound (61\% to $64 \%$ ). Gress et al (3) evaluated 81 patients preoperatively by using dynamic CT and EUS. They found that EUS was superior to dynamic CT for tumour ( $85 \%$ versus $30 \% ; \mathrm{P}<0.0001)$ and node $(72 \%$ versus $55 \% ; \mathrm{P}<0.0001)$ staging, as well as for detecting vascular invasion (93\% versus $62 \% ; \mathrm{P}<0.0001$ ) (Table 3 ). The poor performance of CT in this study population may have been due in part to the inclusion of patients without distant metastases and the use of dynamic instead of helical CT.

The introduction of rapid-scanning helical CT has permitted multiple scans to be obtained through the abdomen during different phases of contrast enhancement. The dualphase technique permits images to be obtained when arterial and pancreatic parenchymal features are optimally visible, and then later when hepatic metastases may be better detected (17). Employing this technique and EUS, Legmann et al (2) studied 30 patients with suspected pancreatic carcinoma. The results did not differ significantly between the two techniques. The sensitivities of CT and EUS were $92 \%$ and 100\%, respectively, for detecting 
TABLE 4

Determination of resectability in pancreatic cancer: Accuracy of endoscopic ultrasound (EUS) versus computed tomography (CT)

\begin{tabular}{lccc}
\hline Author (reference) & $\mathbf{n}$ & EUS (\%) & CT (\%) \\
\hline Legmann et al $(2)^{*}$ & 22 & 89 & 92 \\
Gress et al $(3)^{\dagger}$ & 81 & 93 & 60 \\
\hline
\end{tabular}

${ }^{*}$ Dual-phase helical CT; ${ }^{\dagger}$ Thin-section axial CT. Reproduced with permission from reference 38

tumours; the accuracies at predicting resectability were $92 \%$ and $89 \%$, respectively; and the overall staging accuracies were $93 \%$ for both techniques (Table 4). EUS was found to be more sensitive than CT for detecting hepatic artery encasement but less sensitive for detecting superior mesenteric artery invasion. The authors concluded that thin-section, dual-phase helical CT is the most accurate CT technique for the imaging of pancreatic neoplasms.

Other reports evaluating helical CT have demonstrated less impressive results for predicting resectability ( $86 \%$ for CT versus $76 \%$ for EUS) (18). Midwinter et al (5) performed helical CT and EUS on a series of 48 patients with suspected pancreatic mass. EUS was superior to helical CT (97\% versus $76 \%$ ) at detecting pancreatic tumours. The two techniques were equally able to identify portal and superior mesenteric vein and lymph node involvement. However, EUS was less accurate at detecting superior mesenteric artery invasion, which was also found by Legmann et al (2). On the other hand, EUS was more accurate than CT at detecting distant lymph nodes. This might be an appropriate niche indication for EUS because, if distant lymph nodes were shown by EUS-guided fine needle aspiration (EUS FNA) to harbour malignancy, the cancer could not be cured by resection.

Studies comparing helical CT with EUS yield conflicting results. EUS is clearly the most sensitive technique for the detection of pancreatic masses, particularly when they are smaller than $3 \mathrm{~cm}$ in diameter. The accuracy of EUS for local and regional tumour staging is similar among different series, ranging from $80 \%$ to $90 \%$, whereas the accuracy of helical CT ranges from $56 \%$ to $90 \%$. In a few series, the performance of helical CT has reached the level of EUS, which may reflect a transition toward more sophisticated scanning techniques. EUS and helical CT appear to have the same accuracy for diagnosing mesenteric venous invasion, but EUS is less accurate for diagnosing superior mesenteric artery invasion. In this sense, EUS should be considered for patients in whom a mass has not been identified or in whom CT results are equivocal for the presence of locally advanced disease (eg, vascular invasion). Additionally, EUS FNA of the mass and lymph nodes allows tissue diagnosis.

The role of MRI in the evaluation of patients with pancreatic adenocarcinoma is still evolving. In a multicentre study, dynamic thin-section CT had an accuracy (70\%) similar to that of MRI in predicting the resectability of pancreatic adenocarcinoma (19). Faster helical CT scanners and higher Tesla strength MRI units with various imaging sequences and contrast agents are now providing even better performance characteristics. A recent study demonstrated improvements in the accuracy of both CT (81\%) and MRI (96\%) scans for predicting resectability (20). Further comparative studies are awaited to confirm these results. Arslan et al (21) prospectively compared MRI, MRI angiography and dual-phase helical CT for the evaluation of vascular invasion in 31 patients with pancreatic carcinoma (including nine with vascular invasion). The diagnostic accuracies of the tests were $87 \%, 90 \%$ and $90 \%$, respectively.

\section{ESTABLISHING THE DIAGNOSIS}

The usual technique for confirming the presence of malignant disease is percutaneous biopsy under sonographic or CT guidance. The accuracy of this method is well established (22). It is safe and, in patients not being considered for surgical therapy, straightforward. Concerns have been raised with respect to the potential for seeding of tumour along the needle track; therefore, percutaneous techniques should not be used for lesions that may be resectable. Over the past several years, EUS FNA has been described as a safe method of providing a cytological diagnosis of pancreatic masses. The stomach and duodenum provide an ideal acoustic window to the pancreas. Their proximity permits EUS FNA of pancreatic or peripancreatic abnormalities. EUS FNA may have several advantages, including minimizing the risk of tumour seeding. The needle track would almost always be contained within the resection margins if surgery were to be ultimately performed. Additionally, EUS FNA permits the biopsy of lesions that might not be readily visualized by other techniques.

Several authors have described the utility of EUS FNA in diagnosing pancreatic masses. Results obtained with this technique are promising, reaching an overall sensitivity of $85 \%$ and a specificity of $100 \%(23-31)$. These results are consistent among different institutions. Gress et al (31) recently described their experience with EUS FNA in distinguishing benign from malignant pancreatic masses. In 102 patients with pancreatic mass lesions and prior negative results on CT-guided biopsy or ERCP sampling, 61 had pancreatic cancer. EUS FNA cytology showed malignancy in 57 patients, was negative in 37 , and inconclusive or nondiagnostic in eight. No false positive results were observed. The posterior probability of pancreatic cancer was at least $94.5 \%$ by a conservatively lower $95 \%$ confidence limit after a positive test result. After a definitively negative test result, the posterior probability of pancreatic cancer was $6.9 \%$. The authors reported a high sensitivity (93\%) and specificity $(100 \%)$ of EUS FNA when evaluating patients with pancreatic masses in whom pancreatic cancer was suspected but prior biopsies had been negative.

In addition to establishing a diagnosis when prior biopsy methods have failed, EUS FNA may be able to identify nonperitumoral lymph node (NPTLN) metastases. Limited 
information is available on the frequency of NPTLN and the sensitivity of EUS FNA in this setting. EUS with FNA of identified NPTLN, if performed in patients thought to be resectable based on helical CT, has been shown to be cost effective provided that the frequency of NPTLN involvement was greater than $4 \%$ (32). Prospective studies are needed to determine the sensitivity of EUS FNA for this indication.

EUS FNA can accurately and safely provide a cytological diagnosis of pancreatic masses. This is particularly important for patients who are poor surgical candidates or have signs of locally advanced disease and, therefore, would not be considered for resection. The need for preoperative tissue diagnosis is debatable when imaging tests suggest that the lesion is resectable, and the decision is based on the current practice of the surgeon. Although they are infrequent (less than 1\%), hemorrhage and pancreatitis resulting from EUS FNA can make pancreatic tumour resection more difficult. For this reason, many surgeons prefer not to biopsy the pancreatic mass if it appears to be resectable. Additionally, despite the high sensitivity of EUS FNA, a negative biopsy result does not rule out malignancy and, therefore, should not dissuade the surgeon from operating.

\section{CONCLUSIONS}

The evaluation of the patient with a pancreatic mass has been outlined and suggests that, once the suspicion of a neoplasm has been raised, the major challenge is to determine the resectability of the lesion. Patients who are otherwise considered medically suitable should be offered surgery because it is the only chance for cure. In the best of circumstances, however, the five-year survival ranges from $7 \%$ to $25 \%$ after pancreaticoduodenectomy; the perioperative mortality is less than $2 \%$ and morbidity is $30 \%$ to $50 \%$ at institutions with extended experience (33-36). Although surgical resection alleviates the problems associated with

\section{REFERENCES}

1. Muller MF, Meyenberger C, Bertschinger P, Schaer R, Marincek B. Pancreatic tumors: evaluation with endoscopic US, CT, and MR imaging. Radiology 1994;190:745-51.

2. Legmann P, Vignaux O, Dousset B, et al. Pancreatic tumors: comparison of dual-phase helical CT and endoscopic sonography. AJR Am J Roentgenol 1998;170:1315-22.

3. Gress FG, Hawes RH, Savides TJ, et al. Role of EUS in the preoperative staging of pancreatic cancer: a large single-center experience. Gastrointest Endosc 1999;50:786-91.

4. Mertz HR, Sechopoulos P, Delbeke D, Leach S. EUS, PET, and CT scanning for evaluation of pancreatic adenocarcinoma. Gastrointest Endosc 2000;52:367-71.

5. Midwinter MJ, Beveridge CJ, Wilsdon JB, Bennett MK, Baudouin CJ, Charnley RM. Correlation between spiral computed tomography, endoscopic ultrasonography and findings at operation in pancreatic and ampullary tumours. Br J Surg 1999;86:189-93.

6. Bender GN, Case B, Tsuchida A, et al. Using sector endoluminal ultrasound to identify the normal pancreas when axial computed tomography is falsely positive. Invest Radiol 1999;34:71-4.

7. Pleskow DK, Berger HJ, Gyves J, Allen E, McLean A, Podolsky DK. Evaluation of a serologic marker, CA 19-9, in the diagnosis of pancreatic cancer. Ann Intern Med 1989;110:704-9.

8. Albert MB, Steinberg WM, Henry JP. Elevated serum levels of biliary and/or duodenal obstruction, a pancreaticoduodenectomy should not be performed if preoperative imaging conclusively demonstrates that the disease cannot be completely resected. Although there is general agreement regarding findings that preclude resection (such as liver metastases), surgeons disagree about how much local or regional disease confers unresectability (eg, limited mesenteric venous invasion). Therefore, imaging results may have a variable impact on the decision to operate.

The most streamlined approach to patients with suspected pancreatic neoplasms is to perform a pancreatic protocol helical CT. In patients who have obviously unresectable disease, percutaneous techniques can be used to establish a tissue diagnosis. In patients whose lesions are considered surgically resectable based on the CT, the added benefit of EUS is unknown and is being actively investigated. Unfortunately, many of the available comparative studies between EUS and cross-sectional imaging techniques are biased due to the absence of blinding among the examiners, making it difficult to assess any performance advantage of one test over another. In patients in whom equivocal findings are demonstrated on CT (uncertainty regarding resectability or absence of a mass lesion), EUS helps to determine the presence of a mass lesion and of advanced disease. Patients found to have unresectable disease on EUS should be considered for FNA at the same setting to allow tissue confirmation of the diagnosis.

Collectively, the improvements in imaging tests have essentially relegated the role of ERCP to that of a therapeutic intervention for biliary decompression should surgical therapy not be undertaken. ERCP should not be routinely performed for assisting in the diagnosis of pancreatic neoplasms due to the inherent risks associated with the procedure. ERCP may be helpful, however, when other diagnostic procedures have been unsuccessful or in centres where EUS is not readily available.

tumor marker CA 19-9 in acute cholangitis. Dig Dis Sci 1988;33:1223-5.

9. De Groen PC, Gores GJ, LaRusso NF, Gunderson LL, Nagorney DM. Biliary tract cancers. N Engl J Med 1999;341:1368-78.

10. Rosch T, Lorenz R, Braig C, et al. Endoscopic ultrasound in pancreatic tumor diagnosis. Gastrointest Endosc 1991;37:347-52.

11. Glasbrenner B, Schwarz M, Pauls S, Preclick G, Beger HG, Adler G. Prospective comparison of endoscopic ultrasound and endoscopic retrograde cholangiopancreatography in the preoperative assessment of masses in the pancreatic head. Dig Surg 2000;17:468-74.

12. Baron PL, Aabakken LE, Cole DJ, et al. Differentiation of benign from malignant pancreatic masses by endoscopic ultrasound. Ann Surg Oncol 1997;4:639-43.

13. Nakamoto Y, Higashi T, Sakahara H, et al. Delayed F-18-fluoro-2deoxy-D-glucose positron emission tomography scan for differentiation between malignant and benign lesions in the pancreas. Cancer 2000;89:2547-54.

14. Yasuda K, Mukai H, Fugimoto S, Nakajima M, Kawai K. The diagnosis of pancreatic cancer by endoscopic ultrasonography. Gastrointest Endosc 1988;34:1-8.

15. Rosch T, Braig C, Gain T, et al. Staging of pancreatic and ampullary carcinoma by endoscopic ultrasonography. Comparison with conventional sonography, computed tomography, and angiography. Gastroenterology 1992;102:188-99. 
16. Palazzo L, Roseau G, Gayet B, Vilgrain V, Belghiti J, Fekete F. Endoscopic ultrasonography in the diagnosis and staging of pancreatic adenocarcinoma. Results of a prospective study with comparison to ultrasonography and CT scan. Endoscopy 1993;25:143-50.

17. McNulty NJ, Francis IR, Platt JF, Cohan RH, Korobkin M, Gebremariam A. Multi-detector row helical CT of the pancreas: effect of contrast-enhanced multiphasic imaging on enhancement of the pancreas, peripancreatic vasculature, and pancreatic adenocarcinoma. Radiology 2001;220:97-102.

18. Howard TJ, Chin AC, Streib EW, Kopecky KK, Wiebke EA. Value of helical computed tomography, angiography, and endoscopic ultrasound in determining resectability of periampullary carcinoma. Am J Surg 1997;174:237-41.

19. Megibow AJ, Zhou XH, Rotterdam H, et al. Pancreatic adenocarcinoma: CT versus MR imaging in the evaluation of resectability - report of the Radiology Diagnostic Oncology Group. Radiology 1995;195:327-32.

20. Sheridan MB, Ward J, Guthrie JA, et al. Dynamic contrast-enhanced MR imaging and dual-phase helical CT in the preoperative assessment of suspected pancreatic cancer: a comparative study with receiver operating characteristic analysis. AJR Am J Roentgenol 1999; 173:585-90.

21. Arslan A, Buanes T, Geitung JT. Pancreatic carcinoma: MR, MR angiography and dynamic helical CT in the evaluation of vascular invasion. Eur J Radiol 2001;38:151-9.

22. Welch TJ, Sheedy PF, Johnson CD, Johnson CM, Stephens DH. CTguided biopsy: prospective analysis of 1,000 procedures. Radiology 1989;171:493-6.

23. Faigel DO, Ginsberg GG, Bentz JS, Gupta PK, Smith DB, Kochman ML. Endoscopic ultrasound-guided real-time fine-needle aspiration biopsy of the pancreas in cancer patients with pancreatic lesions. J Clin Oncol 1997;15:1439-43.

24. Bhutani MS, Hawes RH, Baron PL, et al. Endoscopic ultrasound guided fine needle aspiration of malignant pancreatic lesions. Endoscopy 1997;29:854-8.

25. Cahn M, Chang K, Nguyen P, Butler J. Impact of endoscopic ultrasound with fine-needle aspiration on the surgical management of pancreatic cancer. Am J Surg 1996;172:470-2.
26. Chang KJ, Nguyen P, Erickson RA, Durbin TE, Katz KD. The clinical utility of endoscopic ultrasound-guided fine-needle aspiration in the diagnosis and staging of pancreatic carcinoma. Gastrointest Endosc 1997;45:387-93.

27. Erickson RA. Endoscopic ultrasonography: a new diagnostic imaging modality. Am Fam Physician 1997;55:2219-28.

28. Giovannini M, Seitz JF, Monges G, Perrier H, Rabbia I. Fine-needle aspiration cytology guided by endoscopic ultrasonography: results in 141 patients. Endoscopy 1995;27:171-7.

29. Gress FG, Hawes RH, Savides TJ, Ikenberry SO, Lehman GA. Endoscopic ultrasound-guided fine-needle aspiration biopsy using linear array and radial scanning endosonography. Gastrointest Endosc 1997;45:243-50.

30. Wiersema MJ, Vilmann P, Giovannini M, Chang KJ, Wiersema LM. Endosonography-guided fine-needle aspiration biopsy: diagnostic accuracy and complication assessment. Gastroenterology 1997;112:1087-95.

31. Gress F, Gottlieb K, Sherman S, Lehman G. Endoscopic ultrasonography-guided fine-needle aspiration biopsy of suspected pancreatic cancer. Ann Intern Med 2001;134:459-64.

32. Harewood GC, Wiersema MJ. A cost analysis of endoscopic ultrasound in the evaluation of pancreatic adenocarcinoma. Am J Gastroenterol 2001;96:2651-6.

33. Trede M, Schwall G, Saeger HD. Survival after pancreatoduodenectomy. Ann Surg 1990;211:447-58.

34. Cameron JL, Pitt HA, Yeo CJ, Lillemoe KD, Kaufman HS, Coleman J. One hundred and forty-five consecutive pancreatoduodenectomies without mortality. Ann Surg 1993;217:430-8.

35. Livingston EH, Welton ML, Reber HA. The United States' experience with surgery for pancreatic cancer. Int J Pancreatol 1991;9:153-7.

36. Nitecki SS, Sarr MG, Colby TV, Van Heerden JA. Long-term survival after resection for ductal adenocarcinoma of the pancreas: is it really improving? Ann Surg 1994;221:59-66.

37. Fleming ID, Cooper JS, Henson DE, et al. AJCC Cancer Staging Manual. Philadelphia: Lippincott Raven, 1997.

38. Wiersema MJ. Accuracy of endoscopic ultrasound in diagnosing and staging pancreatic carcinoma. Pancreatology 2001;1:625-32. 


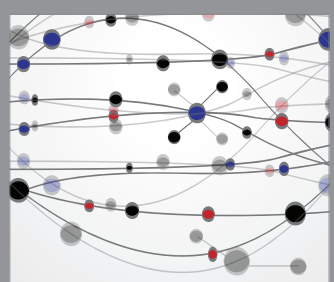

The Scientific World Journal
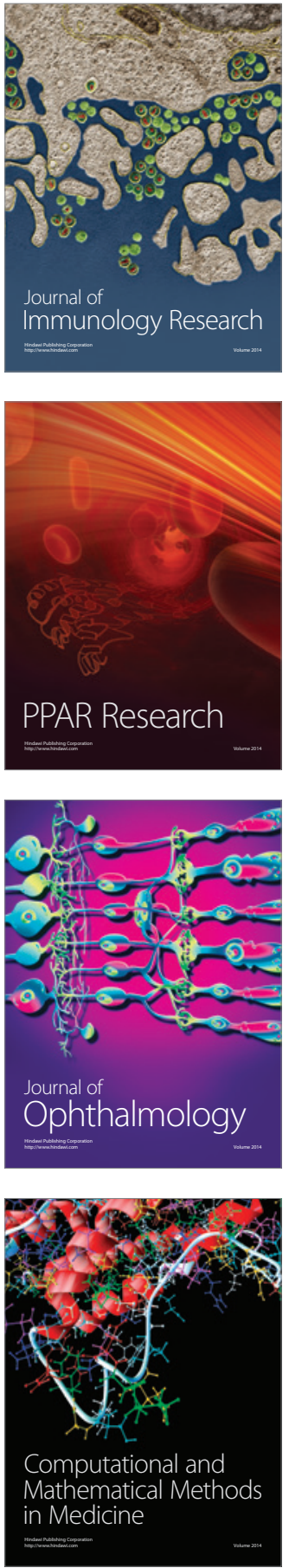

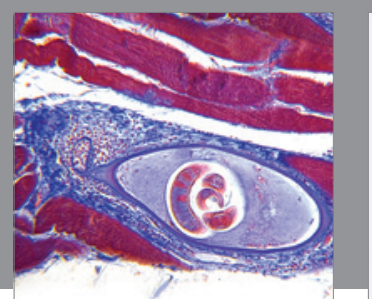

Gastroenterology Research and Practice

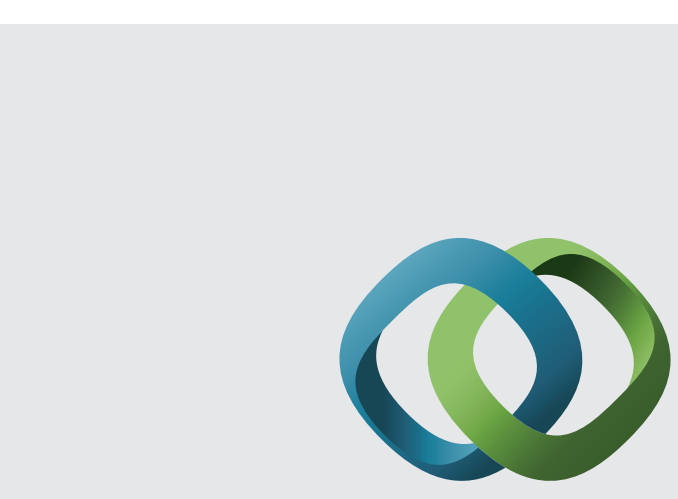

\section{Hindawi}

Submit your manuscripts at

http://www.hindawi.com
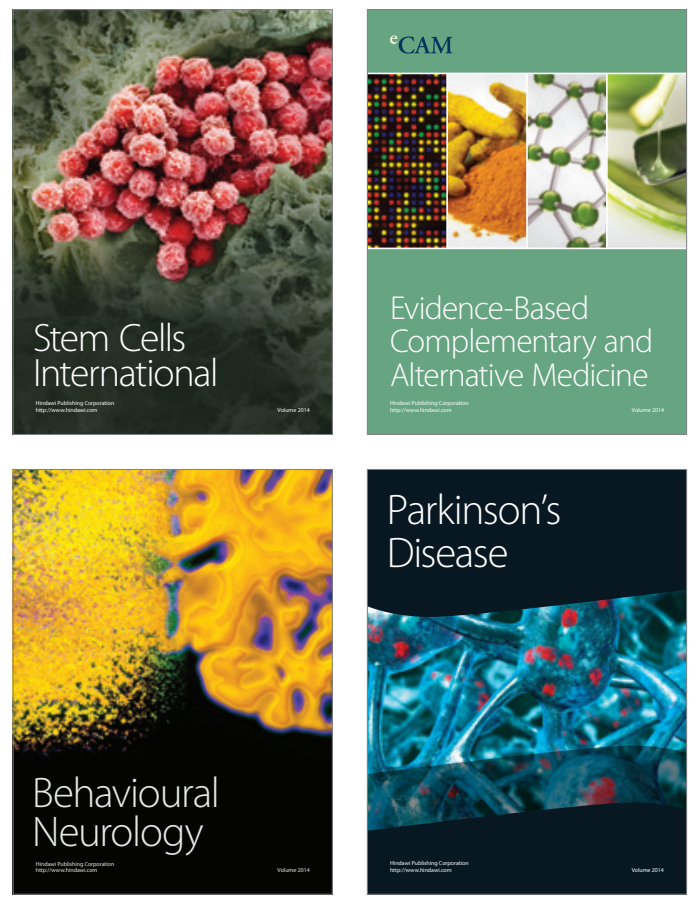
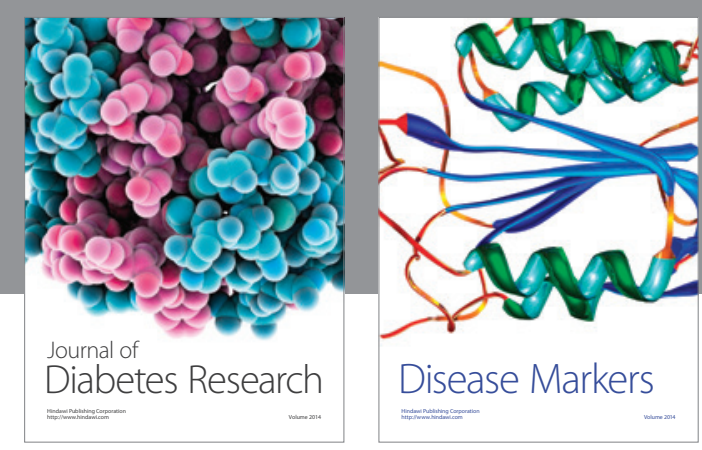

Disease Markers
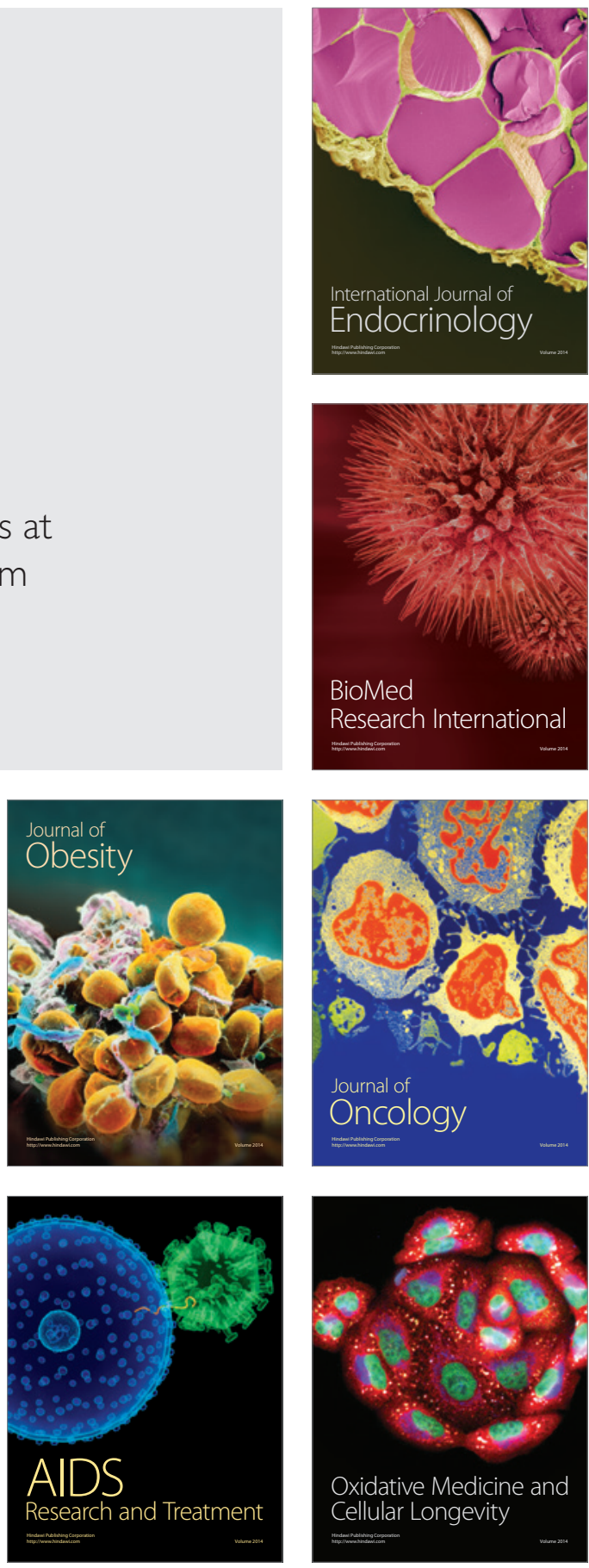